\title{
Detecting Total Quality Management Status and Teamwork Orientation in Al-Yarmouk Teaching Hospital
}

\author{
Zeyad Mustafa Hamed Khawka \\ Department of Business Administration, Faculty of Administration \& Economics, the University of Al-Iraqia, \\ Baghdad, Iraq \\ Email: zeyadkhawka@gmail.com
}

Received 15 February 2016; accepted 13 March 2016; published 16 March 2016

Copyright (C) 2016 by author and Scientific Research Publishing Inc.

This work is licensed under the Creative Commons Attribution International License (CC BY). http://creativecommons.org/licenses/by/4.0/

(c) (i) Open Access

\begin{abstract}
Teamwork in hospitals has been recognized as an important contributor in providing high-quality healthcare for patients. However, it is imperative to understand the factors that affect the relationships among medical patient teams and their perceptions of patient's healthcare quality. The primary objective of this study is to detect the Total Quality Management (TQM) status and teamwork orientation in one of the main Healthcare organizations in Iraq named Al-Yarmouk Teaching Hospital. A questionnaire survey was specially designed as to achieve study objectives. The questionnaire is divided into (60) various items specifically developed to gather information about the study variables. This study was carried out using a cross-sectional survey in which (64) respondents from (Al-Yarmouk Teaching Hospital) had completed a newly developed survey with a response rate of $\mathbf{1 0 0 \%}$. Descriptive statistics, Pearson Correlation, and ANOVA were used for data analysis. The main result of this study was that there was a positive correlation between all TQM dimensions and Teamwork. The survey analysis in addition to survey sample investigation throughout researcher's own observations has revealed that the hospital does not meet TQM requirements. Moreover, the study result on one hand has shown that the impact of teamwork on staff Satisfaction value is $\mathbf{0 . 8 5 4}$, on the other hand it has proved the absence of impact between teamwork and staff perceptions on Quality of Patient Care.
\end{abstract}

\section{Keywords}

Total Quality Management (TQM), Teamwork (TW), Health Care (HC)

\section{Introduction}

Hospitals are the core component of the healthcare sector. They are responsible to provide adequate health ser-

How to cite this paper: Khawka, Z.M.H. (2016) Detecting Total Quality Management Status and Teamwork Orientation in Al-Yarmouk Teaching Hospital. American Journal of Industrial and Business Management, 6, 232-248. 
vice to a very sensitive patient with all complex medical procedure whenever needed. The ultimate goal of hospitals, as a healthcare provider, is to ensure safe, qualified, acceptable, efficient and equal service for their patients. As a result, healthcare services have risen rapidly by both public and private sectors, complementing each other in order to meet the needs of patients and deliver high-quality services ensuring both patients and health professionals satisfaction. Because of the increasingly complex and demanding nature of healthcare services, hospitals and other healthcare organizations are required to focus on Total Quality Management (TQM) approach as a major long-term strategic initiative to continuously improve the quality of patient healthcare, reduce cost and improve efficiency [1]. In healthcare, teamwork plays a critical role in delivering healthcare to patients where healthcare professionals team up to assess patient's conditions and deliver proper healthcare accordingly. Healthcare organizations are designed to accommodate all critical and non-critical cases, so it is crucial to be properly staffed with skilled personnel in order to manage the delivery of their jobs efficiently and assure patient and staff satisfaction. Thus, teamwork oriented culture has been suggested as a promising approach in improving healthcare processes [2]. Research on teamwork across industries is extensive but, within healthcare and nursing, is much more limited. Most studies in healthcare have focused on interdisciplinary teamwork. For example, a study of intensive care staff showed that interdisciplinary teams reporting a higher level of team development had lower patient mortality rates. Brewer found that a "group type hospital culture" resulted in fewer patient falls, and Morey and colleagues discovered that higher teamwork led to fewer errors. An intervention to improve teamwork resulted in a significant improvement in micro albumin testing of diabetic patients. Another research team found a significant positive relationship between measures of hospital teamwork culture and patient satisfaction. Looking specifically at teamwork within nursing (among nurses and assistive personnel) working on a given acute care patient unit, as opposed to healthcare staff members who work on several (or all) patient units (e.g., physicians, physical therapists, pharmacists, etc.), we uncovered scant research. Several investigators have reported a link between nursing staff satisfaction and teamwork, and one study linked higher levels of nursing teamwork with fewer patient falls, lower vacancy, and turnover rates [3].

\section{Literature Review and Related Studies}

This chapter provides a review of the literature that has studied related topics to the concepts of Total Quality Management (TQM) and Teamwork among healthcare environment. The literature review included a search of multiple databases: Science direct, Pubmed, Google scholar and Wiley online library. The keywords utilized in the search engines were: Total quality management, teamwork, teamwork in healthcare and teamwork improvement.

\subsection{Total Quality Management (TQM)}

(TQM) is an important quality improvement philosophy that has been used by organizations all over the world to continuing success through customer satisfaction. TQM emphasizes on the participation of all employees of an organization in continually improving deliverables of processes and the culture in which they work [4]. This approach to management is considered as an important strategy aimed at satisfying the needs of customers [5].

TQM focus not only on the quality of the organization's outcomes but also on the quality of employee. The successful implementation of TQM requires enhancing their commitment, satisfaction, attendance, health and turnover and improving their organizational effectiveness. Companies that used TQM practices brings improvement in productivity, quality and employee development through enhanced creativity, trust, teamwork, communication, training, decision making and innovation. However, the practical effect of TQM principles involves the combined efforts of all staff within the organization while allowing all workers to participate to achieve the quality goals and providing them with tools and training to fulfill their responsibilities. An important aspect of TQM is the successfully involvement of employees in their jobs and empowering them to participate meaningfully in the decision-making activities as well as creating an environment in which they encouraged to work together, enhance sense of accomplishment in jobs and improve personal responsibilities. Hence, TQM, in its total effect, aims to create an environment in which good employee-management relations exist which in turn motivate employee to do their best based on the assumption that employees are in the best position to improve the quality of the daily operating procedure. Consequently, TQM approach focuses on satisfying customer's (internal and external) needs and expectations, continuous improvement, problem prevention, training employees to improve quality and introducing teamwork [6]. 
It is evident that all TQM principles are structured in order to achieve a common goal, customer satisfaction. Thus, the core principles of TQM that should be involved are customer focus, leadership, teamwork, employee participation, continuous quality improvement, training, error prevention and systemization. Top management commitment and employee empowerment are of the most important principles of TQM because they are assumed to have a strong relationship with customer satisfaction [7]. All of these principles if well implemented will result in enhanced satisfaction and organization outcomes.

Although TQM has its roots in manufacturing companies, it has been increasingly used in the healthcare sector as a method of improvement and evaluation by identifying opportunities for improvement that lead to enhanced performance and increased cost effectiveness [8]. The TQM in healthcare can be defined as "the maximization of patient's satisfaction considering all profits and losses to be faced in a healthcare procedure”. TQM can be considered as a management philosophy and management method simultaneously [9].

\subsection{TQM Definition in Healthcare (HC)}

In healthcare services there are three definitions distinguished TQM from other approaches: One is that TQM is a Comprehensive strategy of organizational and attitude change for enabling personnel to learn and use quality methods, in order to reduce costs and meet the requirements of patients and other customers [10]. A second definition by Donabedian refers to quality as the maximization of patient's satisfaction considering all profits and losses to be faced in a healthcare procedure [11]. A third definition given by US theories emphasized that TQM is a management method: TQM/CQI—Continuous Quality Improvement—is simultaneously two things: a management philosophy and a management method [12].

\subsection{Teamwork in Healthcare}

A team can be defined as a complex, social and dynamic entity of two or more individuals adaptability, interdependently and dynamically interact toward common and valued goal [13]. Teams are parts of a larger organizational system which coordinate tasks, roles, and responsibilities to accomplish goals, make decisions and exhibit interdependencies with respect to workflow and outcomes [14].

In the following sections, a conceptual framework for thinking about input factors that affect teamwork effectiveness is presented. We argue that selected TQM principles influence teamwork effectiveness. We would argue further that teamwork process varies with a number of staff, environmental and team characteristics. In the next section, we will examine if there is a relationship between teamwork and how teamwork is related to the perceptions of quality of care and staff satisfaction.

\subsubsection{Top Management Commitment (TM)}

Top management is one of the most important and vital principles in TQM that has a very imperative role in creating an organizational climate that motivates employees. Organizations which rely more on team-based work structures have results in greater productivity and employee performance as teams have been argued to potentially overcome complex problems at work. Teamwork is a significant tool that has a potential to create a high-performance organizations that are efficient and flexible, but it needs to be supported and nurtured over time.

Thus top managers need to recognize and integrate teams within their organizations in a way that motivate members to help each other's for achieving goals and look at strategies for improving teamwork activities. In healthcare, a team with high executive support specifically performs all activates related to patient care better than other teams. Accordingly, teamwork should be institutionalized in the healthcare organizations through the promotion of teamwork culture. This would be achieved by training and enhancing teamwork principles [2].

\subsubsection{Team Training (TR)}

Training is an important element of total quality management. Training in team effectiveness skills and interpersonal relationships are essential complements to knowledge of TQM tools. Thus, an emphasis on training gives staff the ability to work in teams which in turn will improve the chances of successful teamwork [15]. Team-training is defined as a systematic methodology for optimizing targeted teamwork competencies such as communication, coordination and collaboration that combines specific skills, knowledge and attitudes giving the opportunities to use these skills in practice and support the transformation of training activities to the daily care 
environment [16].

\subsubsection{Team Leadership (TL)}

Leadership, as a key principle of TQM, is the most important input factor that supposed frequently in the literature to influence every variable in the team performance. Leadership can be defined as a process of social interaction where the team leaders must have the ability to direct subordinates towards organizational goals, assign tasks and allocate resources, motivate team members and establish a positive environment by encouraging team members to speak freely and ask questions [17].

The leader is not necessarily the most senior [18]. But whoever has experience at hand in organizing, staffing, controlling, directing and planning, knows team members and their roles/responsibilities and make and maintain channels that enables members to do their work [4]. As well, leadership means is evident in creating both financial and human resources in the face of resource constraints [15]. Salas and colleagues have indicated that leadership is one of the core competencies constituting good teamwork through three overarching functions [19]:

(1) Create and maintain team's shared mental models. Team leader is responsible for defining the goals, providing accurate shared understanding of the operating environment and information regarding the resources that are available to the team ensuring each team member understands their roles and how, as a team, they need to respond.

(2) Monitor the internal and external environment of the team to determine what changes are needed ensuring that team members are able to adaptably accommodate for changes in the environment. The leader coordinates team behaviors and interaction by using the information about the environment and providing skill development opportunities as needed.

(3) Establish behavioral and performance expectations including performance monitoring and backup behavior of team members and expect acceptable interaction patterns between team members. Team leader must reestablish adaptive norms, promote information exchange and provide a work environment that is conductive to working on a team.

Moreover, communication effectiveness which refers to the quality of leader-followers as perceived by the followers has been conceptually linked to leadership. An important characteristic of a good leader is the ability to communicate and interact with followers. Effective personal communication skills are a central component of charisma that is critical in determining whether the leader's message will be understood and acknowledged [20]. A number of previous studies have demonstrated the importance of participative leaders in the overall quality strategy which in turn fosters the flow of information and knowledge and contribute to the effectiveness of problem solving process [21]. Teams with leaders who develop the effective engagement of member's capabilities and encourage their participation in decision making and problem-solving processes will foster information sharing among team members [22].

\subsubsection{Participative Leadership}

Participative leadership ranges from simple information sharing or providing input to self-directed responsibilities such as making decisions and solving problems [4]. Participative leadership, also known as employee involvement or participative decision making, refers to the intimate involvement of employees at all levels in the team process. In other words, leaders set policies based on the input and guidance of their subordinate and actively share with them the power and authority in the decision making process, accepting the fact that employees are the facilitators who interact directly with the customers and best satisfy their needs. This technique can be considered as an important motivator for the workers when they have the opportunities to make and implement decision regarding the process in which they participate [7]. Effective team leader can facilitate team effectiveness through the basis of effective engagement of pre-briefs and post-action processes among team members; pre-briefs are meetings that provide the team members the opportunity to clarify member's roles and responsibilities, confirm performance strategies, discuss anticipated issues and focus on key performance prior to initiating performance while post-action is the systematic process of sharing observations and interventions to discuss the team's performance especially after major task engagements [22]. Traditionally, physicians have been assumed to be the natural team leader regardless of their competence. However, new roles are developing in order to enhance clinical productivity, produce desirable staff outcomes and maintain patient satisfaction [23]. In healthcare, the role of leader has extended from solely medical to become more managerial, where the perfor- 
mance of medical units relies not only on leader's experience and acquired technical skills but also behavioral characteristics and ability to manage relationships [24].

\subsubsection{Communication (COM)}

Communication is simply the exchange of information between sender and receiver. Effective teams require reliable communication process which involves an observable exchange of information among team members and subtle interactions of values, powers and attitudes. Team members have to listen frequently to each other in order to develop mutual knowledge and information sharing which enhance collaboration and communication. Formal and informal interchanges in addition to participative decision making will also enhance communication [23]. This concept will facilitate effective teamwork by promoting the continuous updating of the team's knowledge and serves as a coordinating mechanism or supporting structure for teamwork [19].

\subsubsection{Teamwork Process (TP)}

Teamwork process is the core of what contribute to team effectiveness and makes it ultimately successful. Processes describe subtle aspects of patterns and interactions among team members that transfer input into output. Processes therefore, form the knowledge, skills and attitudes (KSAs) and combine collective resources that are critical to team performance effectiveness and facilitate accomplishing team goals. Teamwork varies over time depending on the level of the required team activities so; different knowledge, skills and attitudes are required during team process [14]. In healthcare teams, an appropriate mix and diversity of team member's knowledge, skills, interests and background is required. However, diversity needs to be carefully managed in order to promote effective problem solving and innovation. Each member in the team has a unique position and personality that affect team performance. Hence, all team members should be able to clearly clarify and understand their own roles and duties as well as understand colleague's skills and responsibilities. However, roles need to be flexible enough and interchangeable to accommodate personal development needs, individual differences and membership change specifically in healthcare teams where individuals are unable to choose with whom they work. Accordingly, individuals need to be independent before they can be productive and satisfied. Conflict role that may arise between professional and clinical issues can be avoided when team members work across disciplinary boundaries in the best interests of the patients. Therefore, conflict among team members needs strategies to be managed and avoided. Within a team, good relationships are essential to maintaining effective teams and facilitate a better understanding of team tasks. When individuals are supportive of their colleagues, they offer practical assistance, share information and solve problems collaboratively [21].

\subsubsection{Staff Satisfaction (SS)}

Staff satisfaction is an important issue among healthcare professionals because it has been linked to predictions of their turnover [25]. As well, there is a definite link between staff satisfaction and patient satisfaction. Knowledge of the factors that contribute to staff satisfaction can provide a useful framework for hospital management to create better practice environment for all healthcare professionals. Accordingly, it is important to evaluate staff satisfaction in order to identify problems and try to resolve them before they impact the quality of patient care. Decreased job stress, greater job autonomy, adequate staffing, friendship among members, fairness, communication with supervisors and peers and improved collaboration with medical professionals have all been demonstrated to be related to staff satisfaction [3]. Leadership styles are also directly related to staff satisfaction [22] [26]. Positive inter-professional relationships and cooperation between staff and leader have been shown to improve staff satisfaction and team performance [26]. However, teamwork has been considered as an important contributor for providing an environment to foster staff satisfaction [27].

\subsubsection{Perceptions of Quality of Care (Q)}

It is important for hospital leaders and healthcare providers to work together to develop strategies to improve collaborative relationships among healthcare professionals in order to indirectly enhance the quality of patient care through teamwork [28]. Although there are differences between nurses and physicians in their beliefs about authority, responsibility and role expectations, physician's behaviors contribute to nurse's perceptions of quality of care as well as their satisfaction. Previous studies have found that the quality of care strongly influenced by the good relationship between physicians and nurses and the nature of the daily interactions among them. Thus, improving the collaborative nurse-physician relationship to improve teamwork among them is the heart of any 
organizational improvement action to ensure the quality of patient care [25]. Physicians have a strong influence on the team effectiveness. They often act as the leaders of the healthcare teams. Hence, Physician's attitudes toward healthcare teams may have an important influence on healthcare professional's participation in teams and are likely to be particularly important in determining the quality of patient care. Some physicians view the team as a way of enhancing the effectiveness of care while other view the teams as a waste of time and may distance them from patients. Accordingly, the participation of physicians in teams may vary according to such attitudes and to what extent they feel that team approach improve the quality of patient care [29].

\subsection{Related Studies}

\subsubsection{Ajeigbe et all (2014) Demonstrated "Effect of Nurse-Physician Teamwork in the Emergency Department Nurse and Physician Perception of Job Satisfaction" Los Angeles, CA, USA}

This study demonstrated that the practice of effective nurse-physician teamwork in the emergency department was improved by the administrative support in providing staff with training on teamwork. It also showed that nurse-physician teamwork training and practice in the emergency department were associated with feelings among nurses and physicians of improved job satisfaction. The results pointed to the need to invest resources in nurse-physician teamwork training and in operationalizing teamwork between nurses and physicians in the emergency department. Nurses and physicians could join their skills together in providing good quality care to the patients while maintaining a positive environment for both disciplines to thrive through teamwork practice. Genuine teamwork between nurses and physicians in any healthcare setting could contribute to creating a work environment with reduced hierarchies between them, especially in the emergency department. Teamwork could also serve as an equalizer of hierarchies between nurses and physicians. When such an environment exists, the nurses and physicians could excel and coordinate their skills and efforts to deliver better quality care to the patients, resulting in increased teamwork and job satisfaction for both professions [27].

\subsubsection{Bader (2015) "The Use of Total Quality Management Principles to Improve Teamwork in Healthcare" Amman, Jordan}

The primary objective of this study is to identify the factors that affect the effectiveness of teamwork in the Jordanian health organizations using TQM principles; top management commitment, team training, leader's planning, leader's coordination, leader's motivation and participative leadership in addition to communication. The results showed statistical significant variation in perceived teamwork level in regard to leadership style, preferred working style, medical units and position. However, teamwork has been associated with a lower level of medical errors, a higher level of staff satisfaction and a higher level of quality of care. The study recommends improvement strategies in order to enhance teamwork to advance further in healthcare organizations such as top management support and commitment, continuous improvement, training, customer focus (Patients and staff), staff involvement and medical errors management [2].

\subsection{Research Aim \& Problem}

The aim of the present work is to understand and analyze (TQM) Principles, and their impact on (TW) in Al-Yarmouk Teaching Hospital, in Baghdad, Iraq. In order to attain the research man aim, the research question is formed as follows:

Dose (TQM) Principles has a positive influence on Teamwork in Healthcare in Al-Yarmouk Teaching Hospital?

\subsection{Research Objectives}

The importance of this study derived from the importance of teamwork effectiveness in healthcare. The objectives of this research are:

1) Identify factors that influence the effectiveness of teamwork in the healthcare industry in Iraq health organizations using TQM principles.

2) Investigate if there were significant differences in the respondent's perception on teamwork level.

3) Investigate the impact of teamwork on quality and staff satisfaction among patient healthcare teams.

4) Seek strategies that may be implemented to improve the quality of teamwork. 


\section{Methodology and Research Hypotheses}

According to the review of related literature and the perspective of this study the following hypotheses are assumed:

H1: There is a positive relationship between Dimensions of TQM and Teamwork.

H1a: There is a positive relationship between Top Management commitment and Teamwork.

H1b: There is a positive relationship between Team-Training and Teamwork.

H1c: There is a positive relationship between Leader's planning process and Teamwork.

H1d: There is a positive relationship between Leader's Coordinating Performance process and Teamwork.

H1e: There is a positive relationship between Leader's motivation and Teamwork.

H1f: There is a positive relationship between Participative leadership and Teamwork.

H1g: There is a positive relationship between Communication and Teamwork.

H1h: There is a positive relationship between Teamwork and Staff Satisfaction.

H1i: There is a positive relationship between Teamwork and Staff Perceptions of Quality of Patient healthcare.

H2: The Dimensions of TQM will have a positive influence on Teamwork.

H2a: Top Management commitment will have a positive influence on Teamwork.

H2b: Team-Training will have a positive influence on Teamwork.

H2c: Leader's planning process will have a positive influence on Teamwork.

H2d: Leader's Coordinating Performance process will have a positive influence on Teamwork.

H2e: Leader's motivation will have a positive influence on Teamwork.

H2f: Participative leadership will have a positive influence on Teamwork.

H2g: Communication will have a positive influence on Teamwork.

H2h: Teamwork will have a positive influence on Staff Satisfaction.

H2i: Teamwork will have a positive influence on Staff Perceptions of Quality of Patient healthcare.

Therefore, based on the aforementioned discussions we proposed a conceptual framework (see Figure 1) where TM: Top Management Commitment; TR: Team Training; LP: Leader's Planning; LC: Leader’s coordination; LM: Leader's Motivation; PL: Participative Leadership; COM: Communication; TW: Team work; SS: Staff Satisfaction; Q: Perceptions of Quality of healthcare.

\subsection{Research Design}

The research approach is quantitative (positivist) will be used to answer the research question. Survey method used in this study. Data were collected through questionnaire. Using a Likert scale of (1 - 4) as an approach to facilitate the measurement of perception Relationship latent variables and indicators are reflective. Independent variables reflected TQM nine indicators, namely (1) Top-Management, (2) Team-Training, (3) Leader’s Planning; (4) Leader's Coordinating; (5) Leader's Motivation, (6) Participative leadership; (7) Communication. As much, the impact of teamwork on staff satisfaction and quality of healthcare will be studied through two indictors following as: (8) Staff Satisfaction; (9) Staff Perceptions of Quality of Patient healthcare.

Bearing in mind that the teamwork represents the dependent variable of this study.

\subsection{The Survey Instrument}

The study's instrument used to gather data was descriptive questionnaire. The questionnaire items of this study

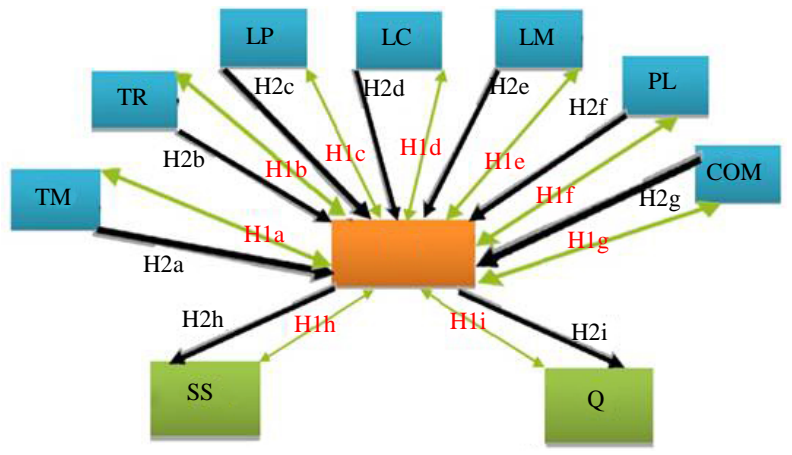

Figure 1. The research conceptual framework. 
were initially derived on the basis of the above-mentioned research, literature and previously published works on teamwork in healthcare. Furthermore, some items were borrowed from Teamwork Perception Questionnaire. The questionnaire consisted of three parts: section (1) General information seeking staff characteristics. The second part is section (2) which collects information about teamwork competencies. Items were linked to specific total quality management principles including top management, team-training, team leadership and member's involvement, communication and teamwork. The constructs of staff satisfaction and quality of patient care also were included. Each item in section (2) had four alternative answer choices ranging from strongly disagree to strongly agree.

\subsection{Analysis and Discussion}

This chapter describes the survey sample and setting, data collection procedures, the general characteristics of the respondents and data analysis methodology. Results that were obtained regarding the aforementioned conceptual framework and hypotheses testing are also presented. In addition, the variation of teamwork in regard to background variables will be examined in the next sections. Moreover, an overview of the study and significant findings will be discussed. Data of 65 questionnaires were analyzed using the Statistical Package for the Social Science (SPSS) version 15.

\subsection{Study Sample}

The simple random sampling method is employed for selecting the research sample. The 75 questionnaires survey was distributed to employees in the Yarmouk Teaching Hospital; only 65 questionnaires survey were returned. The Staff from Al-Yarmok Teaching Hospital in Baghdad is randomly selected to participate in this study. Only Emergency Room, Surgery, Internal Diseases, Pediatrics, Gynecology, Dentistry, and medical-Surgical wards were targeted. The accessible population of this thesis consisted of all anesthesiologists, nurses and physicians, other members of the teams who worked on units such as, physical therapist, radiology technicians, laboratory technicians and pharmacists).

Table 1 clarifies that most of the answers to Position's questions are Anesthesiologists at percent $26.2 \%$ of total, and most respondents were we found in age category of (31 - 40) years old, and mostly males with about (6 - 10) years' Experience, their Current Unit is Internal Diseases, most of them working in groups, and 43.1\% of them been involved in Teamwork Training Course.

\subsection{Descriptive Statistics}

The order of importance is calculated for total quality management variables using the coefficient of variation, arithmetic mean and standard deviation.

Table 2 shows that team work process (TW) occupied the first place, in comparison with other dimensions.

Table 2 shows that the first is Team-Training because it has the lower value of coefficient of variation and it was equal to $8.66 \%$, Teamwork has $7.50 \%$ of coefficient of variation and that's mean it's most Homogeneity.

\subsection{Testing Hypotheses of Correlation}

The significant of correlation between the TQM dimensions and Teamwork is summarized in Table 3 as follows:

Referring to the correlation in Table 3, it shows that all Hypotheses of Correlation are significant at the 0.05 and the power of Pearson correlation of Leader's planning process and Teamwork is 0.777 and that Considered a strong relation, and the power of Pearson correlation between Teamwork and Staff Satisfaction is 0.632 and there is no correlation between Teamwork and Staff Perceptions of Quality of Patient Care.

\subsection{Testing Hypothesis of a Significant Impact}

\subsubsection{The Significant Impact between Dimensions of Total Quality Management \& Teamwork Will Be Tested Based upon the Following Hypotheses \\ H2a: Top Management will have a positive influence on Teamwork. \\ H2b: Team-Training will have a positive influence on Teamwork.}


Table 1. Analysis of demographic variables.

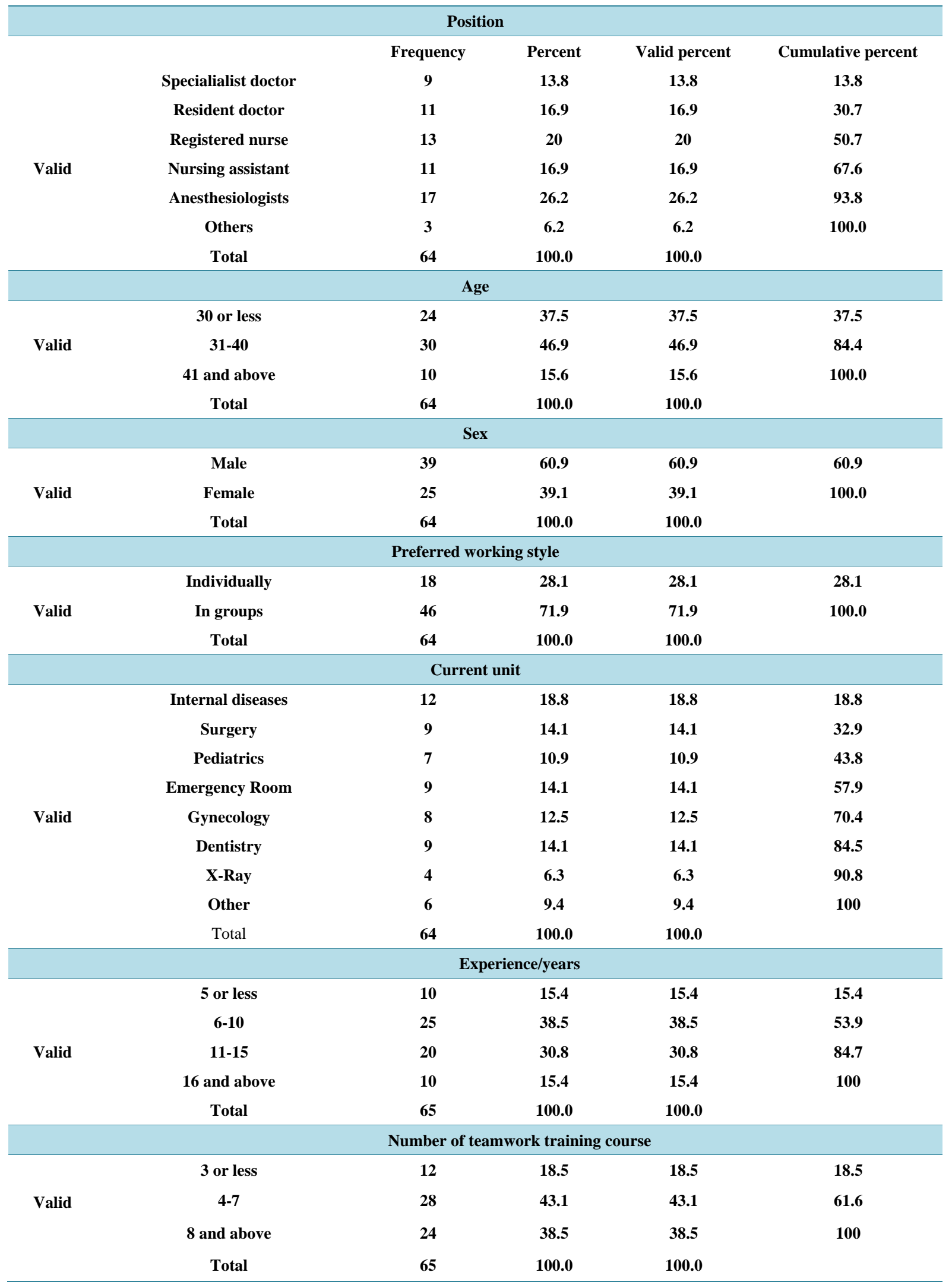


Table 2. Order of importance statistics.

\begin{tabular}{|c|c|c|c|c|c|}
\hline Dimensions & $\mathbf{N}$ & Mean & Std. deviation & $\begin{array}{c}\text { Coefficient of } \\
\text { variation }\end{array}$ & Order of importance \\
\hline TM & 64 & 3.05 & 0.26427 & $8.66 \%$ & Third \\
\hline TR & 64 & 3.082 & 0.24521 & $7.96 \%$ & first \\
\hline $\mathbf{L P}$ & 64 & 3.0906 & 0.43047 & $13.93 \%$ & Fifth \\
\hline LC & 64 & 3.1458 & 0.51819 & $16.47 \%$ & Seventh \\
\hline LM & 64 & 3.0625 & 0.48181 & $15.73 \%$ & Sixth \\
\hline PL & 64 & 3.0625 & 0.31074 & $10.15 \%$ & fourth \\
\hline COM & 64 & 3.1607 & 0.25262 & $7.99 \%$ & Second \\
\hline TW & 64 & 3.1219 & 0.20966 & $7.50 \%$ & \\
\hline SS & 64 & 3.0547 & 0.31329 & $10.26 \%$ & \\
\hline $\mathbf{Q}$ & 64 & 3.0905 & 0.21061 & $6.81 \%$ & \\
\hline Valid N (list wise) & 64 & & & & \\
\hline
\end{tabular}

Table 3. Relationship correlation.

\begin{tabular}{|c|c|c|c|}
\hline Hypotheses & Relationship & $\begin{array}{c}\text { Pearson } \\
\text { correlation }\end{array}$ & Accept/Reject \\
\hline H1a & Top Management and Teamwork & $0.572 *$ & Accept \\
\hline H1b & Team-Training and Teamwork & $0.548 *$ & Accept \\
\hline H1c & Leader's planning process and Teamwork & $0.777 *$ & Accept \\
\hline H1d & $\begin{array}{c}\text { Leader's Coordinating Performance process and } \\
\text { Teamwork }\end{array}$ & $0.700 *$ & Accept \\
\hline H1e & Leader's motivation and Teamwork & $0.718 *$ & Accept \\
\hline H1f & Participative leadership and Teamwork & $0.712 *$ & Accept \\
\hline H1g & Communication and Teamwork & $0.290 *$ & Accept \\
\hline H1h & Teamwork and Staff Satisfaction & $0.632 *$ & Accept \\
\hline H1i & $\begin{array}{l}\text { Teamwork and Staff Perceptions of Quality of } \\
\text { Patient Care }\end{array}$ & 0.116 & Reject \\
\hline
\end{tabular}

H2c: Leader's planning process will have a positive influence on Teamwork.

H2d: Leader's Coordinating Performance process will have a positive influence on Teamwork.

H2e: Leader's motivation will have a positive influence on Teamwork.

H2f: Participative leadership will have a positive influence on Teamwork.

H2g: Communication will have a positive influence on Teamwork.

Table 4 shows that all the dimensions of total quality management influence Teamwork in the research sample (Al-Yarmouk Teaching Hospital). Table 4 clarifies that there is an impact between dimensions of total quality management \& Teamwork because the significant value is less than (0.05). Therefore the hypotheses will be accepted and the null hypotheses are rejected.

\subsubsection{The Significant Impact between Teamwork \& Staff Satisfaction Will Be Tested Based upon the Following Hypothesis}

H2h: Teamwork will have a positive influence on Staff Satisfaction.

Tables 5-7 clarify that there is an impact of Teamwork on Staff Satisfaction because the significant value is less than (0.05). And value of $\mathrm{R}^{2}$ is 0.4 , that's mean the Teamwork may explain what percentage of $40 \%$ of the changes in Staff Satisfaction, and the value of impact is 0.854 . Therefore the hypotheses will be accepted and the null hypotheses are rejected.

\subsubsection{The Significant Impact between Teamwork \& Staff Perceptions of Quality of Patient Care Will Be Tested Based upon the Following Hypothesis}

H2i: Teamwork will have a positive influence on Staff Perceptions of Quality of Patient Care. 
Table 4. Impact between dimensions of (TQM) \& (TW).

\begin{tabular}{|c|c|c|c|c|}
\hline \multicolumn{4}{|c|}{ Teamwork } & \multirow{2}{*}{$\begin{array}{c}\text { Dependent variable } \\
\text { Independen } \\
\text { variables }\end{array}$} \\
\hline Test & B & $\mathbf{R}^{2}$ & $\mathbf{F}$ & \\
\hline sig. & 0.502 & 0.327 & 30.115 & Top Management \\
\hline sig. & 0.518 & 0.301 & 26.641 & Team-Training \\
\hline sig. & 0.419 & 0.604 & 94.573 & Leader's planning process \\
\hline sig. & 0.313 & 0.489 & 59.432 & $\begin{array}{l}\text { Leader's coordinating } \\
\text { Performance process }\end{array}$ \\
\hline sig. & 0.346 & 0.516 & 66.033 & Leader's motivation \\
\hline sig. & 0.531 & 0.507 & 63.646 & Participative leadership \\
\hline sig. & 0.266 & 0.084 & 5.672 & Communication \\
\hline
\end{tabular}

Table 5. Model summary.

\begin{tabular}{ccccc}
\hline Model & R & R square & Adjusted R square & Std. error of the estimate \\
\hline 1 & $0.632^{\mathrm{a}}$ & 0.400 & 0.390 & 0.24465 \\
\hline
\end{tabular}

a. Predictors: (Constant), TW.

Table 6. ANOVA ${ }^{\mathrm{b}}$.

\begin{tabular}{|c|c|c|c|c|c|c|}
\hline & Model & Sum of squares & Df & Mean square & $\mathbf{F}$ & Sig. \\
\hline \multirow{3}{*}{1} & Regression & 2.473 & 1 & 2.473 & 41.311 & $0.000^{\mathrm{a}}$ \\
\hline & Residual & 3.711 & 62 & 0.060 & & \\
\hline & Total & 6.184 & 63 & & & \\
\hline
\end{tabular}

a. Predictors: (Constant), TW; b. Dependent Variable: SS.

Table 7. Coefficients ${ }^{\mathrm{a}}$.

\begin{tabular}{|c|c|c|c|c|c|}
\hline \multirow{2}{*}{ Model } & \multicolumn{2}{|c|}{ Unstandardized Coefficients } & \multirow{2}{*}{$\begin{array}{c}\text { Standardized } \\
\text { Coefficients } \\
\text { Beta }\end{array}$} & \multirow[t]{2}{*}{$\mathbf{t}$} & \multirow{2}{*}{ Sig. } \\
\hline & B & Std. Error & & & \\
\hline (Constant) & 0.411 & 0.412 & & 0.997 & 0.322 \\
\hline TW & 0.854 & 0.133 & 0.632 & 6.427 & 0.000 \\
\hline
\end{tabular}

a. Dependent Variable: SS.

Also, Table 8 shows the value of $\mathrm{R}^{2}$ equals 0.014 , this means that the Teamwork \& Staff Perceptions of Quality of Patient Care may explain the percentage of $1.4 \%$. In the research sample (Al-Yarmouk Teaching Hospital), it is a very small percentage. Table 9 and Table 10 clarify that there is no impact between Teamwork \& Staff Perceptions of Quality of Patient Care because the significant value is more than 0.05 . Therefore the hypotheses will be rejected and the null hypotheses are accepted as shown in Table 11.

All results can be illustrated in Figure 2.

\section{Conclusions, Implications, and Future Research Directions}

\subsection{Discussion}

The current study has explored the factors that affect teamwork level of medical staff who work in (Al-Yarmouk Teaching Hospital) among the most top management commitment, training, communication, as well as leadership processes including planning, coordination, motivation and participative leadership. Also, the impact of teamwork on staff satisfaction and perceptions of quality of patient care has been examined. The research finding concludes that the Dimensions of Total Quality Management are connected in a positive with teamwork and also these dimensions have an impact on Teamwork. Teamwork has also had a positive correlation with the staff satisfaction and an impact on the sample under the search as well. Unfortunately the research did not prove that 
Table 8. Model summary.

\begin{tabular}{ccccc}
\hline Model & $\mathrm{R}$ & R Square & Adjusted R Square & Std. Error of the Estimate \\
\hline $\mathbf{1}$ & $\mathbf{0 . 1 1 6}^{\mathrm{a}}$ & $\mathbf{0 . 0 1 4}$ & $\mathbf{0 . 0 0 2}$ & $\mathbf{0 . 2 1 0 8 6}$ \\
\hline
\end{tabular}

a. Predictors: (Constant), TW.

Table 9. ANOVA ${ }^{\mathrm{b}}$.

\begin{tabular}{ccccccc}
\hline & Model & Sum of Squares & Df & Mean Square & F & Sig. \\
\hline & Regression & 0.038 & 1 & 0.038 & 0.851 & $0.360^{\text {a }}$ \\
& Residual & 2.757 & 62 & 0.044 & & \\
& Total & 2.794 & 63 & & & \\
\hline
\end{tabular}

a. Predictors: (Constant), TW; b. Dependent Variable: Q.

Table 10. Coefficients ${ }^{\mathrm{a}}$.

\begin{tabular}{|c|c|c|c|c|c|c|}
\hline & \multirow{2}{*}{ Model } & \multicolumn{2}{|c|}{ Unstandardized Coefficients } & \multirow{2}{*}{$\begin{array}{c}\text { Standardized } \\
\text { Coefficients } \\
\text { Beta }\end{array}$} & \multirow[t]{2}{*}{$\mathbf{T}$} & \multirow{2}{*}{ Sig. } \\
\hline & & B & Std. Error & & & \\
\hline \multirow{2}{*}{1} & (Constant) & 2.764 & 0.355 & & 7.775 & 0.000 \\
\hline & TW & 0.106 & 0.115 & 0.116 & 0.923 & 0.360 \\
\hline
\end{tabular}

a. Dependent Variable: Q.

Table 11. Test impact.

\begin{tabular}{lll}
\hline Hypotheses & Test & Null Hypotheses \\
\hline H2a & Accepted & There is impact between Top Management and Teamwork. \\
H2b & Accepted & There is impact between Team-Training and Teamwork. \\
H2c & Accepted & There is impact between Leader's planning process and Teamwork. \\
H2d & Accepted & There is impact between Leader's Coordinating Performance process and Teamwork. \\
H2e & Accepted & There is impact between Leader's motivation and Teamwork. \\
H2f & Accepted & There is impact between Participative leadership and Teamwork. \\
H2g & Accepted & There is impact between Communication and Teamwork. \\
H2h & Accepted & There is impact between Teamwork and Staff Satisfaction. \\
H2i & Rejected & There is no impact between Teamwork and Staff Perceptions of Quality of Patient Care.
\end{tabular}

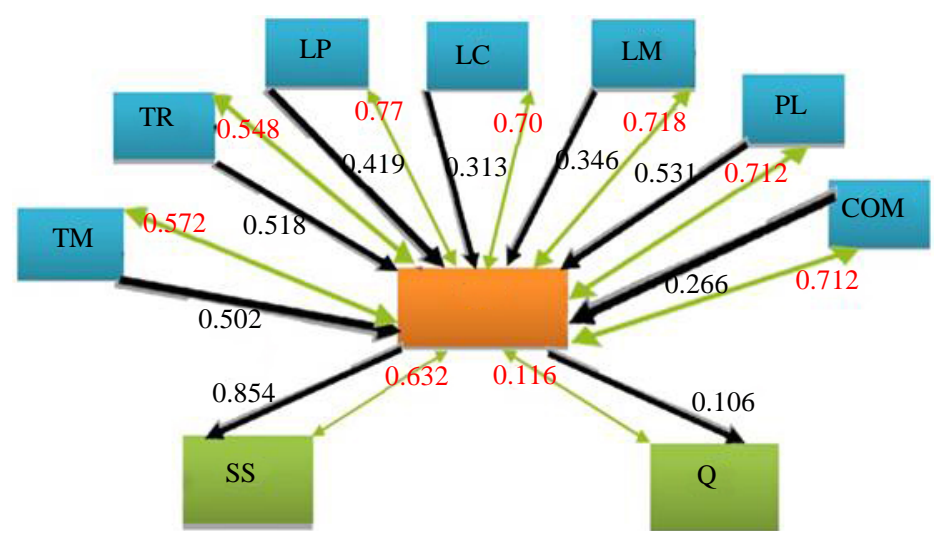

Figure 2. Correlation and positive influence value. 
Teamwork has a correlation or Influence on perceptions of quality of patient care.

\subsection{Limitation}

The author feels that the main challenge faces in this research is that there is a misunderstanding and deficiency in (TQM) implementation and lack of experts in this field in Al-Yarmouk Teaching Hospital.

\subsection{Future Work}

Top management shall urge the quality department staff to immediately start with (TQM) awareness training courses to all employees in Al-Yarmok Teaching Hospital.

\subsection{Conclusion}

The conclusions drawn out of this research are that the Team-Training has got less standard deviation value of 0.24521 with a mean value of 3.082. This shows homogeneity in the answers and means that the trend of questioners is neutral, therefore the Teamwork comes with standard deviation and mean values of 0.20966 and 3.1219 respectively. The data analysis demonstrates a strong positive correlation between both the Leaders' planning process and Teamwork with the value of 0.777 and the Teamwork and Staff Satisfaction with the value of 0.632, while no correlation was detected between Teamwork and Staff Perceptions of Quality of Patient Care. The research reveals the existence of the impact of Participative leadership on Teamwork and the value of that impact is 0.531; and the value of that impact of Teamwork on Staff Satisfaction is 0.854. Finally the research declares that there is no impact between Teamwork \& Staff Perceptions of Quality of Patient Care because the significant value shall be more than 0.05 .

\section{References}

[1] Patel, G. (2009) Total Quality Management in Healthcare. The MIDAS Journal. http://hdl.handle.net/10380/3062

[2] Bader, M.M. (2015) The Use of Total Quality Management Principles to Improve Teamwork in Health Care. M.Sc. Thesis, Industrial Engineering, the Faculty of Graduate Studies, Jordan University of Science and Technology, 1-21.

[3] Kalisch, B.J. and Lee, K.H. (2010) The Impact of Teamwork on Missed Nursing Care. Nursing Outlook, 58, $233-241$. http://dx.doi.org/10.1016/j.outlook.2010.06.004

[4] Evans, J.R. and Lindsay, W.M. (2007) The Management and Control of Quality. 7th Edition, Thomson South-Western, UK.

[5] Chakravarty, A., Parmar, N.K. and Ranyal, R.K. (2001) Total Quality Management-The New Paradigm in Health Care Management. Medical Journal Armed Forces India, 57, 226-229. http://dx.doi.org/10.1016/S0377-1237(01)80049-6

[6] Karia, N. and Asaari, M.H. (2006) The Effects of Total Quality Management Practices on Employees’ Work-Related Attitudes. The TQM Magazine, 18, 30-43. http://dx.doi.org/10.1108/09544780610637677

[7] Ramesh, N. and Ravi, A. (2013) TQM Tools and Techniques in Promoting Team Working Culture in the Manufacturing Organizations. International Journal of Productivity and Quality Management, 12, 466-479. http://dx.doi.org/10.1504/IJPQM.2013.056777

[8] Vanrooyen, M.J., Grabowski, J.G., Ghidorzi, A.J., Dey, C. and Straneg, G.R. (1999) The Perceived Effectiveness of Total Quality Management as a Tool for Quality Improvement in Emergency Medicine. Academic Emergency Medicine, 6, 811-816. http://dx.doi.org/10.1111/j.1553-2712.1999.tb01212.x

[9] Al-Ali, A.M. (2014) Developing a Total Quality Management Framework for Healthcare Organizations. International Conference on Industrial Engineering and Operations Management, Bali, 7-9 January 2014, 889-898.

[10] Overtveit, J. (2000) Total Quality Management in European Healthcare. International Journal of Healthcare Quality Assurance, 13, 74-90. http://dx.doi.org/10.1108/09526860010319523

[11] Donabedian, A. (1989) Institutional and Professional Responsibilities in Quality Assurance. Quality Assurance in Healthcare, 1, 3-12. http://dx.doi.org/10.1093/intqhc/1.1.3

[12] William, A.S and Johnson, J.K. (2013) Mclaughlin and Kaluzny’s Continuous Quality Improvement in Healthcare. 4th Edition, Jones \& Bartlett Learning, London.

[13] O’Leary, K.J., Sehgal, N.L., Terrell, G., and Williams, M.V. (2011). Interdisciplinary Teamwork in Hospitals: A Review and Practical Recommendations for Improvement. Journal of Hospital Medicine, 1-7. 
[14] Fernandez, R., Kozlowski, S., Shapiro, M. and Salas, E. (2008) Toward a Definition of Teamwork in Emergency Medicine. Academic Emergency Medicine, 15, 1101-1112. http://dx.doi.org/10.1111/j.1553-2712.2008.00250.x

[15] Ojha, A.K. (2000) Total Quality Management: How Can We Make the Implementation Effective? Vikalpa, 25, 19-29.

[16] Weaver, S.J., Dy, S., M. and Michael A. Rosen, M.A. (2014) Team-Training in Healthcare: A Narrative Synthesis of the Literature. BMJ Quality \& Safety, 23, 359-372. http://dx.doi.org/10.1136/bmjqs-2013-001848

[17] Kay, J., Maisonneuve, N., Yacef, K. and Reimann, P. (2006) The Big Five and Visualizations of Team Work Activity. In: Ikeda, M., Ashley, K.D. and Chan, T., Eds., Intelligent Tutoring Systems: Proceedings of the 8th International Conference, ITS 2006, Springer, 197-206.

[18] Siassakos, D., Fox, R., Katherine Bristowe, K., Angouri, J., Hambly, H., Robson, L. and Draycott, T.J. (2013) What Makes Maternity Teams Effective and Safe? Lessons from a Series of Research on Teamwork, Leadership and Team Training. Acta Obstetricia et Gynecologica Scandinavica, 92, 1239-1243. http://dx.doi.org/10.1111/aogs.12248

[19] Salas, E., Sims, D.E. and Burke, C.S. (2005) Is There a "Big Five” in Teamwork? Small Group Research, 36, 555-599. http://dx.doi.org/10.1177/1046496405277134

[20] Neufeld, D.J., Wan, Z. and Fang, Y. (2010) Remote Leadership, Communication Effectiveness and Leader Performance. Group Decision and Negotiation, 19, 227-246. http://dx.doi.org/10.1007/s10726-008-9142-x

[21] Awuor, E.O., Doris M.W. and Kimuthia, D.M. (2013) Total Quality Management Practices in Selected Private Hospitals in Nairobi, Kenya. European Journal of Business and Management, 5, 33-44. http://dx.doi.org/10.1016/S1048-9843(01)00093-5

[22] Zaccaro, S.J., Rittman, A.L. and Michelle A. Marks, M.A. (2001) Team Leadership. The Leadership Quarterly, 12, 451-483.

[23] Mickan, S. and Rodger, S. (2000) Characteristics of Effective Teams: A Literature Review. Australian Health Review, 23, 201-208. http://dx.doi.org/10.1071/AH000201

[24] Lin, B.Y., Hsu, C.C., Juan, C., Lin, C., Lin, H. and Chen, J. (2011) The Role of Leader Behaviors in Hospital-Based Emergency Departments’ Unit Performance and Employee Work Satisfaction. Social Science \& Medicine. 72, 238246. http://dx.doi.org/10.1016/j.socscimed.2010.10.030

[25] Chang, W.Y., Ma, J.-C, Chiu, H.-T, Lin, K.-C. and Lee, P.-H. (2009) Job Satisfaction and Perceptions of Quality of Patient Care, Collaboration and Teamwork in Acute Care Hospitals. Journal of Advanced Nursing, 65, 1946-1955. http://dx.doi.org/10.1111/j.1365-2648.2009.05085.x

[26] Andrews, D.R., Richard, D.C.S., Robinson, P., Celano, P. and Hallaron, J. (2012) The Influence of Staff Nurse Perception of Leadership Style on Satisfaction with Leadership: A Cross-Sectional Survey of Pediatric Nurses. International Journal of Nursing Studies, 49, 1103-1111. http://dx.doi.org/10.1016/j.ijnurstu.2012.03.007

[27] Ajeigbe, D.O., McNeese-Smith, D., Phillips, L.R. and Leach, L.S. (2014) Effect of Job Satisfaction. Journal of Nursing \& Care, 3, 1-6.

[28] McCulloch, P., Mishra, A., Handa, A., Dale, T., Hirst, G. and Catchpole, K. (2009) The Effects of Aviation-Style Non-Technical Skills Training on Technical Performance and Outcome in the Operating Theatre. Quality \& Safety in Health Care, 18, 109-115. http://dx.doi.org/10.1136/qshc.2008.032045

[29] Heinemann, G.D., Schmitt, M.H. and Farrell, M.P. (1999) Development of Attitudes toward Health Care Teams Scale. Evaluation \& the Health Professions, 22, 123-142. http://dx.doi.org/10.1177/01632789922034202 


\section{Appendix A: Questionnaire*}

Section 1/Background Information: please complete the following information.

\begin{tabular}{|c|c|c|c|c|}
\hline 1 & Gender & Male & & female \\
\hline 2 & Age & 30 or less above. & $31-40$ & 41 and \\
\hline \multirow{3}{*}{3} & \multirow{3}{*}{ Position } & Specialialist Doctor & \multicolumn{2}{|r|}{ Nursing Assistant } \\
\hline & & Resident Doctor & & Anesthesiologists \\
\hline & & Registered Nurse & & Other \\
\hline \multirow{4}{*}{4} & \multirow{4}{*}{ Current Unit } & Internal Diseases & & Gynecology \\
\hline & & Surgery & & Dentistry \\
\hline & & Pediatrics & & X-Ray \\
\hline & & Emergency Room & & Other \\
\hline \multirow{2}{*}{5} & \multirow{2}{*}{ Years of Experience } & 5 or less & & $6-10$ \\
\hline & & $11-15$ & & 16 and above \\
\hline 6 & Preferred Work Orientation & Individually & & In Groups \\
\hline 7 & Number of Teamwork Training Courses & 3 or less & $4-7$ & 8 and above \\
\hline
\end{tabular}

Section 2/Teamwork: Please place a check mark $(\sqrt{ })$ in the box that corresponds to your level of agreement to the statements regarding your team.

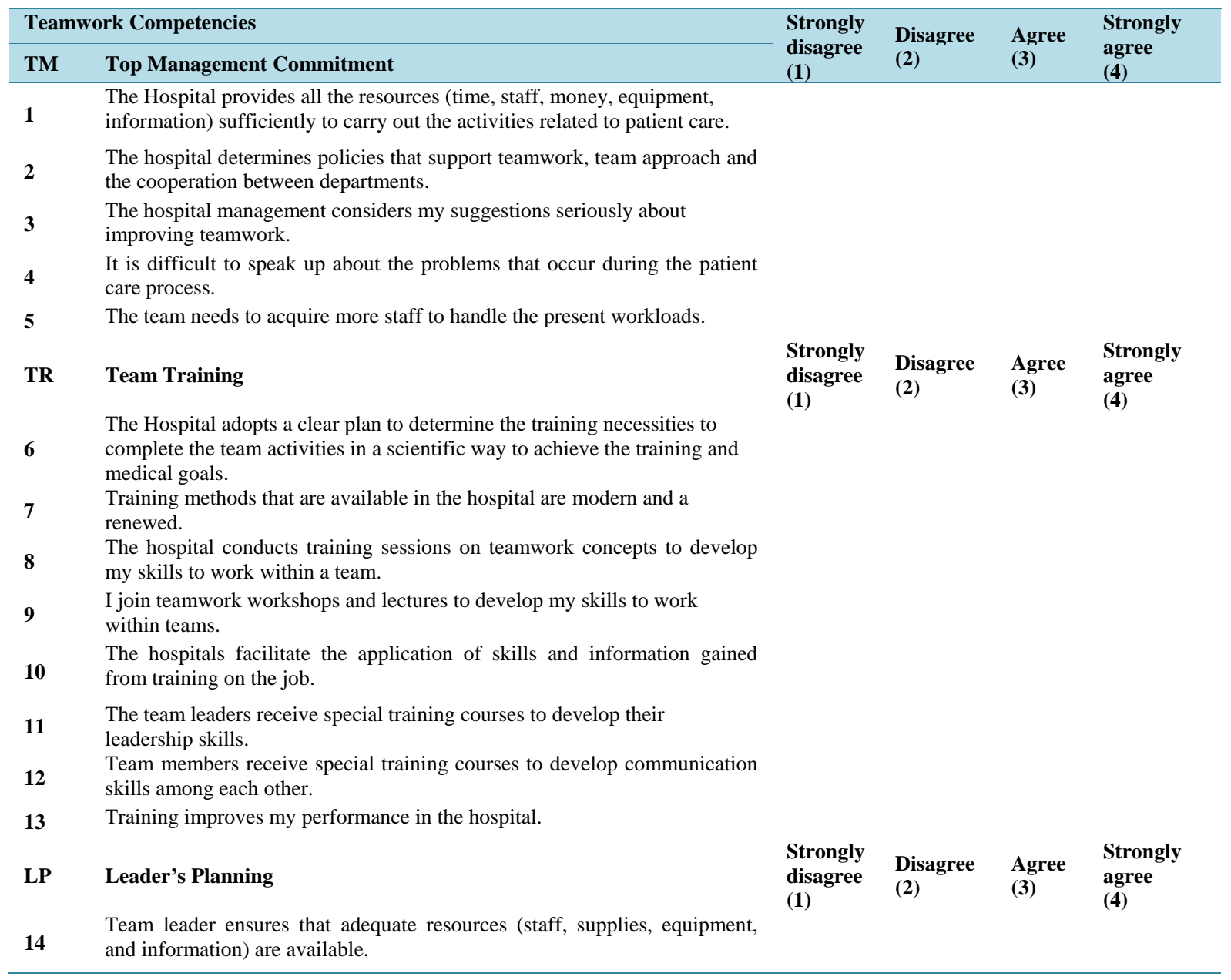




\section{Continued}

\begin{tabular}{ll}
\hline 15 & Team leader informs the team of important issues at shift changes \\
(complications in patient's conditions and/or change in plan of treatment). \\
$\mathbf{1 6}$ & Team leader takes time to meet with staff to develop a plan for patient care. \\
$\mathbf{1 8}$ & Team leader gives clear directions about how to do work. \\
$\mathbf{L C}$ & Leader's Coordination \\
$\mathbf{1 9}$ & Team leader coordinates efforts of individuals and ensures that team members \\
$\mathbf{2 0}$ & $\begin{array}{l}\text { Team leach other out when necessary. } \\
\text { of care. }\end{array}$ \\
$\mathbf{2 1}$ & $\begin{array}{l}\text { Team leader is available for consultation on problems and is willing to assist } \\
\text { team members throughout the process of care. }\end{array}$ \\
$\mathbf{2 2}$ & Team leader communicates with other teams' leaders (if present) to ensure \\
$\mathbf{2 3}$ & better coordination of efforts.
\end{tabular}

\section{LM Leader's Motivation}

25 Team leader provides the opportunities to discuss the unit's performance after an event.

26 It is easy to ask questions when there is something ambiguous.

Team leader gives positive/negative feedback to each team member individually about her/his performance.

Team leader views honest mistakes as meaningful learning opportunities and encourages staff to develop their skills and abilities.

\section{PL Participative Leadership}

Strongly disagree

Team leader considers staff inputs and opinions when making decisions about patient care.

Team leader gives me the sufficient power to perform all tasks related to patients care.

31 Team leader intervenes in decisions taken by team members.

32 Team leader exercise the powers delegated to the members.

33 Members feel that their role is marginal indispensable to influence the decisions in the team.

34 Team leader set policies based on the input and guidance of team members.

\section{COM Communication}

Strongly disagree (1)

\section{Disagree
(2)}

\section{Agree}

(3)

Strongl

(4)
35

Team members follow a standardized method of sharing information when handing off patients.

36

Team members use common medical terminology when communicating with each other.

37

Team members ensure that the information is well understood by others.

38

39

40
You acknowledge and confirm requests through verbal or nonverbal behavior.

You exchange information or opinions with inexperienced members to ensure team effectiveness.

Hospital management provides effective and sophisticated means of communication between team members.

Hospital Management provides information system to provide the team with the data necessary to take the right decision at the right time with the appropriate quantity and quality.

\section{Disagree Agree Strongl \\ (2) \\ (3)}




\section{Continued}

\begin{tabular}{|c|c|}
\hline TW & Teamwork \\
\hline 42 & Team members understand their roles and responsibilities. \\
\hline 43 & Team members understand the role and responsibilities of each other. \\
\hline 44 & $\begin{array}{l}\text { Team members are similar to each other (e.g. Knowledge, skills, abilities, } \\
\text { personalities). }\end{array}$ \\
\hline 45 & Team members effectively correct each other’s mistakes. \\
\hline 46 & $\begin{array}{l}\text { When the workload becoming (or is about to become) extremely heavy, } \\
\text { team members assist each other and work together to get the work done. }\end{array}$ \\
\hline 47 & Disagreements in this clinical area are appropriately resolved. \\
\hline 48 & $\begin{array}{l}\text { Team members work with a great deal of flexibility so adapt to the } \\
\text { changing needs }\end{array}$ \\
\hline 49 & Team members accept decisions made by the leader. \\
\hline 50 & $\begin{array}{l}\text { Team members integrate their skills together in providing good quality care } \\
\text { to the patients. }\end{array}$ \\
\hline 51 & There are feelings of superiority between the physicians and nurses. \\
\hline
\end{tabular}

\section{SS Staff Satisfaction}

$\begin{array}{llll}\begin{array}{l}\text { Strongly } \\ \text { disagree }\end{array} & \text { Disagree } & \begin{array}{l}\text { Agree } \\ \text { (2) }\end{array} & \begin{array}{l}\text { Strongly } \\ \text { agree }\end{array} \\ \text { (1) } & & & \text { (4) }\end{array}$

52 I am satisfied with working in this hospital.

$53 \quad$ I am satisfied with my current job.

54 I am satisfied with the quality of collaboration that I experienced with my team leader.

55 I am satisfied with the quality of collaboration that I experienced with my team members.

\section{Q Quality of Care}

$\begin{array}{llll}\text { Strongly } & \text { Disagree } & \text { Agree } & \begin{array}{l}\text { Strongly } \\ \text { disagree }\end{array} \\ \text { (1) } & \text { (2) } & \text { (3) } & \text { (4) }\end{array}$

56 The team approach improves the quality of care to patients.

$\begin{array}{llll}\begin{array}{l}\text { Strongly } \\ \text { disagree }\end{array} & \text { Disagree } & \text { Agree } & \begin{array}{l}\text { Strongly } \\ \text { agree }\end{array} \\ \text { (1) } & \text { (2) } & \text { (3) } & \text { (4) }\end{array}$

57 Developing a patient care plan with other team members avoids errors in delivering care.

58 Health professionals working on teams are more responsive than others to the emotional and financial needs of patients.

59 Health professionals working on teams gain valuable tips on patient care from one another.

60 The team approach impedes health professionals to meet the needs of patients.

*It was adapted by the researcher. Source: Bader, M.M. (2015) “The Use of Total Quality Management Principles to Improve Teamwork in Health Care”. Thesis Submitted in Partial Fulfillment of the Requirements for the Degree of M.Sc. in Industrial Engineering, The Faculty of Graduate Studies, Jordan University of Science and Technology, 82-86. 